\title{
Future Problem Solving Learning Environment at Indonesian Universities for Physical Education Courses: An Analysis
}

\author{
Moh. Fathur Rohman, Moch. Asmawi, Yusmawati ${ }^{*}$ \\ Faculty of Sport Science, Universitas Negeri Jakarta, Jakarta, 13220, Jakarta Timur, Indonesia
}

Received September 22, 2020; Revised November 19, 2020; Accepted November 27, 2020

\section{Cite This Paper in the following Citation Styles}

(a): [1] Moh. Fathur Rohman, Moch. Asmawi, Yusmawati, "Future Problem Solving Learning Environment at Indonesian Universities for Physical Education Courses: An Analysis, "Universal Journal of Educational Research, Vol. 8, No. 12B, pp. 8433-8439, 2020. DOI: 10.13189/ujer.2020.082650.

(b): Moh. Fathur Rohman, Moch. Asmawi, Yusmawati (2020). Future Problem Solving Learning Environment at Indonesian Universities for Physical Education Courses: An Analysis. Universal Journal of Educational Research, 8(12B), 8433-8439. DOI: 10.13189/ujer.2020.082650.

Copyright $\mathrm{C} 2020$ by authors, all rights reserved. Authors agree that this article remains permanently open access under the terms of the Creative Commons Attribution License 4.0 International License

\begin{abstract}
One of the human abilities that is needed in the future is to be sensitive to the environment. With this sensitivity, it will make someone wiser in determining attitudes at this time with consideration of the future. This study aims to analyze the learning environment at the university as a place for someone to prepare for the future whether it includes aspects of future problem solving. Data were collected by survey method. The subjects of this study were lecturers and students in the physical education learning subject with total subject of 6 universities, 12 lecturer and 240 students. The instrument used to carry out the analysis was developed based on five indicators that specifically emphasize the future problem solving process in the classroom, 1) Creating an Environment of Respect and Rapport, 2) Establishing a Culture for Learning to Encourage Student Engagement and Responsibility, 3) Managing Classroom Procedures, 4) Encouraging Appropriate Student Behavior, 5) Organizing the Physical Environment. The results of the observation of the implementation of learning show that the learning environment has been well managed, the five components of the learning environment have been implemented, but the integration of future problem solving components has not been found in the learning environment, student involvement in the second indicator has not been optimally carried out, this is reflected in student activities in which they are mostly receptors. The results of the analysis of the learning device documentation used by the lecturers have
\end{abstract}

used a scientific approach, but not even one has used a future problem solving approach. Lecturers and students are very interested in developing future problem solving learning models.

Keywords Future Problem Solving, Learning Environment, Higher Education, Physical Education

\section{Introduction}

A person's competence is very important to be continuously prepared, adjusted and developed [1]. Identify some future skills that a person needs to have, including personal skills such as initiative, resilience, responsibility, risk-taking, and creativity; social skills such as teamwork, networking, empathy, and compassion; and learning skills such as managing, organizing, meta-cognitive skills and rising from failure.

On the other hand, the idea of global competence articulates the knowledge and skills that students need in the 21 st century. Globally competent students have the knowledge and skills to: Investigate the World: Globally competent students are aware, curious, and interested in learning about the world and how it works. Recognize Perspectives: Globally competent students recognize that they have certain perspectives, and others may or may not 
share them. Communicate Ideas: Globally competent students can communicate effectively, verbally and non-verbally, with diverse audiences. Take Action: Globally competent students have the skills and knowledge to not only learn about the world, but also make a difference in the world [2].

One of the institutions that plays an important role in preparing someone with such competences is educational institutions. Educational institutions have a strategic role in interpreting various competencies through a good and precise learning process. The competencies that a person wants to master will be reflected in certain qualifications. Graduate qualifications are designed at each level of education that has been regulated by the government in the KKNI (Indonesian National Qualification Criteria). Thus, to develop the qualifications of a bachelor's degree education graduate, lecturers must develop learning that is able to fully involve students in the process of solving problems in the present and in the future. Students will be better prepared to welcome the future with the various experiences they have while studying.

The development of the dynamics of community life which is increasingly global today, marked by the progress of science, causes the need for re-actualization in the way of looking at education. Education is the main means for a nation to be able to develop in line with the current of globalization by having higher education quality standards that are adjusted to changes in the dynamics of society, because education is a means of mastering science.

Learning carried out in tertiary institutions must be able to develop all the potential of students. Potential hard skills and soft skills are developed thoroughly and harmoniously. In terms of knowledge and science (academically) students master well, besides that they must also have social awareness, think creatively, and behave well (non-academically).

Currently in many tertiary institutions learning that is carried out focuses more on hard skills such as understanding certain material concepts, while on the other hand in real life, many more complex real problems await students. The learning process at the undergraduate level is at the heart of the birth of qualified, competent, and competitive scholars. Learning is an integrated process in the education system. The learning process has the basic meaning of teaching students to achieve certain competencies that are desired in order to become complete human beings, such as the mandate of national education goals. Learning is designed to provide experiences for learners to be able to live well in the future.

The learning process consists of several components which according to KKNI there are at least three, including learners, learners, and learning resources. These three components are the main components in creating an interactive learning environment.

The structure of the learning model at least consists of approaches, strategies, methods, techniques and tactics. The learning model provides an overview of the design of the learning environment that the lecturer wants to create. The learning model regulates various learning activities that will be carried out with certain rules in order to be able to achieve the specified learning objectives. The structure of the learning model has four special characteristics, including: 1) rational theoretical and logical formulated by educators, 2) learning objectives to be achieved, 3) teaching steps that will be used so that the learning model can be implemented optimally, 4) learning environment created so that learning objectives are achieved [3].

Learning is designed to provide various learning experiences for students in solving various problems. Problems are things that can never be separated from life. Each problem has its own characteristics, it's just that each solution can vary. When there is a disagreement between what you want also the actual conditions, that's when it becomes a problem. Due to the complexity of problems in this life, it is necessary to have effective, efficient, creative, and correct problem-solving skills that must be possessed by students. In learning, these skills are assisted by a problem based learning model. Learning has a close relationship with problem solving, "problem solving and learning are tightly linked and both are driven by impasses" [4]. The learning process and problem-solving have similarity, namely that there is something that hinders the achievement of goals. Whether it comes from yourself or from outside.

Problems are very easy to find in life, both on an internal and even global scale. Internal problems, such as finding a job, getting a decent salary, finding a life partner, completing work assignments, and others. Meanwhile, global problems include prevention of globalization, humanitarian crises, religious tolerance, environmental pollution (water, land, air), and others. However, for every problem that arises there must be room to find a solution. Optimism in finding the right and creative solution to a problem is very important for everyone to have. A problem occurs when, under certain circumstances, the goal state needs to be achieved, and no routine method of solution is available [5].

Problem solving is a basic skill needed by students today. Guided by the latest research in problem solving, changing professional standards, new job demands, and new changes in learning theory, educators and trainers revise the curriculum to include integrated learning environments that encourage students to use higher order thinking skills, and in particular, problem solving skills [6]. A learning environment with problem skills content is usually called problem-based learning (PBL).

Problem-based Learning (PBL) is a learning environment where problems encourage learning. That is, before students learn some of their knowledge they are given a problem. The problem is posed so that students 
find that they need to learn some new knowledge before they can solve the problem. Some examples of problem-based learning environments include: a) research projects, b) Engineering design projects that are more than just a synthesis of previously learned knowledge.

Greiff et. al. tated in his research that "problem solving has received wide public attention as an important competency in modern society. In large-scale assessments of paper-based pencil-based analyzes are first included (eg. Program for International Student Assessment, PISA 2003 [7]) [8]. With increasing interest in more complex situations, the focus has shifted to interactive problem solving (eg, PISA 2012 [9]) which requires the identification and control of complex systems. Going forward, collaborative problem solving is the next step in assessing problem-solving abilities (for example, PISA 2015). With these findings, it can be seen that the problem solving skills themselves continue to develop along with the increasingly complex problems that exist in the real world.

As the nation's next generation, students are not only required to be able to solve their current problems, but are also expected to be able to identify, analyze, recognize and develop creative solutions to problems in the future, for example, the next 10 or 20 years. To facilitate this in learning, the term future problem solving (FPS) is known. According to research conducted by Wasis on 466 respondents (lecturers and teachers), it was found that the majority of respondents $(62 \%)$ had integrated FPS in their learning through questions about the realities that exist in everyday life [10].

Future Problem Solving (FPS) is an international educational program for students of all ages ranging from P-12 that focuses on developing creative thinking skills. In particular, it centers on problem identification skills and positive solutions to the problem. More than that, FPS aims to provide youth with the skills to design and promote a positive future for the communities in which they live [11]. The aim of future problem solving is basically to develop critical, creative and futuristic thinking skills. It challenges students to apply their imagination and thinking skills to some of the significant problems facing the world now, and the future, equipping them with the skills and vision needed to anticipate, understand and solve problems related to these problems, helping them achieve having a positive impact. in future society.

Future Problem Solving is a program in which students learn to solve the complex scientific and social problems of the future through the use of creative and comprehensive thinking processes. FPS takes students beyond rote memorization. This process challenges students to apply the information they get through research to some of the most complex problems facing society. They are asked to think, make decisions and, in some cases, to implement solutions.
Bonnie L. Cramond and Elizabeth C. Fairweather stated "future problem solving is offered as a program that can be incorporated into existing content to support the learning of academic content, introduce and strengthen critical skills, address social and emotional needs, and encourage innovative thinking tendencies as well" [12].

Although many scenarios are faced exclusively in the future, the problem-solving methods used are equally applicable to many of the complexities faced in today's world. FPS allows a broad scope for creative and futuristic thinking and encourages students to not only analyze and synthesize the information they had before them, but also to express their ideas cohesively and fluently. In FPS, teamwork, critical thinking, decision making and time management are vital skills.

Developed 'learn - how - to - learn' skills are becoming increasingly important in an era of rapid change, especially in the workplace. The future availability of information is bound to be so great that knowledge of 'empirical facts' in a particular area will be of no use. The advantage, then, is, in a world of increasingly fierce competition, to go to those who can adapt to change the fastest and are able to come up with the most creative yet logical ideas. Future Problem Solving Processes enhance such skills.

To achieve its goals and objectives, FPS offers a number of different options to meet the different needs of students, schools and other community groups. All of these alternatives encourage creativity amidst teamwork, systematic and critical thinking, and the development of a lateral view of real-world situations.

The main purpose of developing a learning model is to make students learn. Learning is the acquisition of new mental schemes, knowledge, abilities, skills, and skills, which can be used to solve potentially more successful problems, continue experiential decision making, which enhances "doing" as the basis for achieving an effective understanding of knowledge [13].

In addition, to increase the competence and competitiveness of graduates, education systems and practices in tertiary institutions must be designed to produce visionary undergraduate university graduates. During their college years, students must experience for themselves how to deal with their problems effectively. Students also need to develop information literacy and use it to solve their problems, especially in an era where global citizens become e-citizens who need to equip themselves with e-learning skills. Students also need to be responsive to problems that occur in society, and know how to focus on the problem areas they are most likely to solve, without precluding the possibility of working interdisciplinary with other professionals from other relevant fields.

Three global movements have become trends in the last two decades related to the development of new 21 st-century learning models, including motivation for 
new learning models, specific competencies and skills needed to function effectively in the twenty-first century, and pedagogy needed to stimulate that ability. He further states that "there is no single approach to educating young people in the twenty-first century" [1]. The development of modern 21 st century learning cannot be separated from changes in competence at every time. Every time has its own characteristics, and now, we are living in the 21 st century which is often called the knowledge and information century [1].

Learning models can increase the interactions that occur during the learning process, given that interaction is an important element of any learning environment (face-to-face class-based education, online synchronous / asynchronous, or mixed models), in addition, by utilizing technology in certain learning models believed to be able to improve the quality of interaction in learning [14]. However, there are different interaction patterns of the learning system in various learning models, both passive and active models. In the research conducted by Carlson and Falk, a range of active and passive learning models was used to develop third-level interactive videodiscs for core education and tertiary inservice in the human service profession [15]. This means that, using the help of technology, allows various patterns of interaction in learning. Active and passive learning models can also be integrated into one learning model.

Likewise with the learning approach. Learning approaches can be collaborated in a learning model in certain ways. The concept of a holistic approach that is centered on lecturers, students, and learning resources collaborated with the concept of future problem solving which demands the performance of hard skills and soft skills to reflect the characteristics of modern, visionary learning. The collaboration between the two of them becomes a framework for a learning model that will greatly help lecturers to develop a quality and meaningful learning process.

\section{Method}

The purpose of this study was to describe the characteristics of the learning environment carried out by lecturers who taught physical education learning subjects. Has the learning environment applied the concept of future problem solving concepts? The subjects in this study were lecturers and students who were carrying out physical education learning courses. The basic theory qualitative research methodology is used in observation with inductive and deductive analysis.

The study population was 6 classes in 6 universities including 12 lecturers and 240 4th semester students.

The questions in this study are designed to obtain information that can be used to describe the feasibility of learning currently being carried out with an emphasis on the presence of elements of future problem solving. The questions asked include:

1) How do lecturers design their learning to support optimal competency linkages with a visionary approach?

2) How do the Lecturers play a role in facilitating students to learn to solve problems?

3) What are the lecturers' expectations to motivate students to learn?

4) What is the form of active collaboration between lecturers and students or between students?

5) How are the supporting learning resources to support the achievement of existing competencies?

6) How do lecturers use various approaches in their learning?

Sources of data were obtained from lecturers and student observation notes, document exploration, and interviews. Data were collected from two lecturers based on the lessons they have carried out. All the qualitative information collected is then coded to separate out the central information [16].

Data analysis was carried out by coding, grouping and categorizing the data obtained through instruments designed to give meaning to data and provide explanations related to findings. Researchers re-categorize, regroup and even re-interpret them, until they find a representative description. [17]. Evaluation in each process and learning tools can solve learning problems [18]

In the end, all the data obtained after going through the data analysis process were concluded to be a description of the characteristics of the future problem solving-based learning environment in the physical education learning subject.

\section{Result and Discussion}

A system of letters and numbers is used to encode information obtained during observation. The codes are used to sort and categorize information based on 6 research questions consisting of the following themes: classroom management, rules and procedures, classroom climate or atmosphere, learning targets, collaborative groups, student worksheets, technology, project-based learning, based learning. problem, future problem solving based learning.

This section provides a summary of the characteristics of the learning environment that integrates elements of future problem solving. To ensure the confidentiality of the classes observed will be referred to as A1, A2, A3, B1, $\mathrm{B} 2, \mathrm{~B} 3$.

\section{Question 1}

The learning design developed by the two lecturers is in the form of a curriculum document. Both developed learning tools with the same guidelines, namely the 2019 
Higher Education Curriculum Guidelines that apply in Indonesia. All formats have been adapted to the existing guidelines, but on more technical devices the authorization of roles becomes more specific. The authorization in question is in the preparation of a learning device framework in general following national guidelines, on the graduate profile tool and learning outcomes following university guidelines, while the specific achievements and learning implementation plans are developed based on faculty guidelines, study programs and the expectations of the two lecturers (development). Lecturer A said that "all guidelines have been socialized by the government and universities so that they become uniform, except for lecture program units". Meanwhile, lecturer $\mathrm{B}$ received provisions for the preparation of learning tools at the PEKERTI (Instructional Engineering Skills Improvement Program) workshop which was carried out by certain authorized institutions.

Lecturers A and B are accustomed to developing curricula and using various learning models in their learning designs. However, none of them have ever used a future problem solving learning model. Lecturer A already knows but doesn't really understand it, but lecturer B doesn't really know it at all. However, both lecturers are familiar with cooperative learning models and project based learning. "I often use cooperative learning and project based learning models" as revealed by lecturer A.

The 21st century learning model has also been applied in learning, however, it has not led much to the goal of preparing students to be more prepared and sensitive to their roles in the future.

\section{Question 2}

In all classes, the lecturer starts learning by saying hello and asking how he is. In classes B1 and B3, sometimes it starts immediately with a presentation.

All classes have been divided into groups with different topics. Groups are adjusted according to the amount of material in one class. In classes $\mathrm{B} 1$ and $\mathrm{A} 3$ there are students who get two opportunities to join different groups.

In classes $\mathrm{A} 1, \mathrm{~A} 2, \mathrm{~A} 3, \mathrm{~B} 2$ and $\mathrm{B} 3$, the lecturers often convey their motivation to learn at the end of the meeting. Lecturer A, for example, provides motivation by conveying the sentence from the character "as good as knowledge is useful", while lecturer A also often asks students to convey the impression of learning.

The form of communication established by the lecturers in all classes is good, but the quality of interaction is still very minimal. This was found in classes $\mathrm{A} 1, \mathrm{~A} 3, \mathrm{~B} 1$, and B2 where often the questions thrown by the lecturer did not get a response, so the lecturer was forced to improvise with simpler sentences, like what lecturer A did "OK, I'll make it easier" .

Related to presenting problems in learning, the lecturer gave examples of learning problems commonly encountered in physical education learning according to the examples of cases in books and some of their experiences. Students respond to all classes when they encounter new problems in class, showing confusion and being silent. This is very natural to encounter when someone gets into a problem directly without any preparedness. The ability to face problems with these situations is indeed one of the 21 st century competencies that students must possess.

The problem presented by the lecturer was in the form of a problem with a well structure type, where the problem and how to solve it were clear. For example, lecturer B presented a problem by asking "if you became a physical education teacher, what would you do to make learning more interesting?", Or what lecturer A did by presenting the case "Teacher $\mathrm{X}$ already has varied learning resources, but students still reluctant to actively participate in learning, what things can cause it and what are your solutions?".

Lecturers have presented problems in their learning, but they are still limited to well structure problems. Meanwhile, the problem with the ill-structure characteristics does not appear to be presented.

\section{Question 3}

The motivation given to students is carried out verbally by the lecturers in all classes.

For example, Lecturer A gave motivation by saying "when you can master the material well, you will become a professional teacher", or what lecturer B said "being a teacher is a noble job, currently teachers have received more attention from the government, their welfare. more increasing".

The motivation given is in the form of an example of phenomena in society. This is very good, but not all students will be interested in verbal motivation.

The type of motivation chosen will certainly greatly affect the meaning of learning. In visionary learning, motivation is given by directly involving students in a challenging and interesting activity, so they want to achieve it someday with enthusiasm. For example, having a dialogue with a character, or doing a study in a prestigious place in the world of education, or experiencing teaching at school directly.

\section{Question 4}

All classes experience cooperative learning. By dividing the groups and making presentations in front of the class in turn.

There are still very few active students in class, in groups with an average of 4 members, only one to two members who actually work and contribute to the completion of the assignment. 
Interaction only occurs between subjects in the class, namely students and lecturers. Interactions with other learning sources are still not visible in all classes. For example in class B3, even though they have been instructed to retrieve information from other sources, most student assignments are obtained only from the internet. The same is true of all the other classes.

\section{Question 5}

The main learning resources used by the two lecturers are the lecturers themselves, text modules and the internet. There are no electronic-based learning resources that are specifically used to support learning.

The use of electronic learning resources is only based on directions from the lecturer for students to search through existing search engines.

The available learning resources by design are only textbooks.

Learning resources have an important role in supporting future problem solving based learning, especially to support the ability to solve problems in a variety of creative ways, not getting lost in ignorance due to lack of materials.

\section{Question 6}

Through documentation studies, the learning tools developed by the two lecturers have used various learning models. Especially in using scientific-based learning models.

Cooperative learning, project based learning, and inquiry are the models most often used by lecturers.

In one semester, lecturer A used three types of models, while lecturer B used 4 models.

Among the existing models, there is no single model that uses a problem-based model, especially the future problem solving model.

Although sometimes lecturers present problems in class, actually these problems are not problems that are deliberately designed in learning.

Problem-based learning will give students the opportunity to practice solving problems in an effective and efficient way, specially problems related to his future profession. Therefore, lecturers need to design their learning in this direction.

\section{Conclusions}

Based on the results of the analysis conducted by the researcher, all existing classes have not used a problem solving-based learning model. All classes use a scientific approach and several times use a problem-based approach, problems, problems presented in learning are only and incidental.

Lecturers have played very good role in learning, however, student interaction in solving problems has not been found in high proportions. Often lecturers have to help students in solving existing problems or cases.

The interaction in the classroom has met the criteria for various interactions in learning. Namely with lecturers, between students, and students with learning resources. However, the resulting interactions in each interaction have not been observed in detail. Researchers cannot observe information that can be processed into long-term memory of students and even to the stage of developing the information obtained.

Learning resources owned by lecturers already exist, some are ICT-based. ICT-based content is still very much needed to help facilitate student learning according to their respective learning styles.

The learning models used have mostly shown scientific interactions and cooperation between students. Collaboration is carried out by students in completing group assignments to be presented. Of the four groups, it was seen that most often only one or two group members were actively working, some groups did show very good performance with the interaction of all group members, but only a few were found in all classes. This neuroscience-based and cooperative learning strategy is a potential which is further developed into problem-solving based learning in the future.

Given this potential, the researchers suggest conducting further research by developing problem-solving based learning models in the future. Besides that, observations about the interaction between students and various learning sources need further tracing.

\section{REFERENCES}

[1] C. L. Scott, "The Futures of Learning 3: what kind of pedagogies for the 21 st century?," Educ. Res. Foresight, pp. 1-21, 2015, doi: 10.1016/j.pse.2015.08.005.

[2] Asia Society, "What is Global Competence? | Asia Society." 2018.

[3] N. Khosim, "Model-Model Pembelajaran - Google Buku." Suryamedia Publishing, 2017.

[4] D. Langley, Pat Choi, "Learning recursive control programs from problem solving," J. Mach. Learn. Res., vol. 7, pp. 493-518, 2006.

[5] R. E. Mayer, "Should There Be a Three-Strikes Rule against Pure Discovery Learning? The Case for Guided Methods of Instruction," Am. Psychol., vol. 59, no. 1, pp. 14-19, 2004, doi: 10.1037/0003-066X.59.1.14.

[6] J. K. Rob Foshay, "Principles for Teaching Problem Solving," PLATO Learn., pp. 1-16, 2003.

[7] Organisation for Economic Co-operation and Development (OECD), "Learning for tomorrow's world: first results from PISA 2003," Author, Paris, Fr., p. 477 pp, 2004, doi: 10.1787/9789264006416-en. 
[8] S. Greiff, D. V. Holt, and J. Funke, "Perspectives on Problem Solving in Educational Assessment: Analytical, Interactive, and Collaborative Problem Solving," J. Probl. Solving, 2013, doi: 10.7771/1932-6246.1153.

[9] Y. Kogure, PISA 2012 Assessment and Analytical Framework. 2013.

[10] W. D. Dwiyogo, “Analisis Kebutuhan Pengembangan Model Rancangan Pembelajaran Berbasis Blended Learning (PBBL) Untuk Meningkatkan Hasil Belajar Pemecahan Masalah," J. Pendidik. DAN PEMBELAJARAN, vol. 21, no. 1, pp. 71-78, 2013.

[11] FPSI, "What is FPSPI - Future Problem Solving Program International." 2018.

[12] L. Shavinina, The Routledge International Handbook of Innovation Education. New York: Routledge, 2013.

[13] J. M. Alonso, Fernando López, Genoveva Manrique, Daniel Viñes, "An instructional model for web-based e-learning education with a blended learning process approach," $B r . J$. Educ. Technol., vol. 36, no. 2, pp. 217-235, 2005, doi:

\subsection{1/j.1467-8535.2005.00454.x.}

[14] T. C. R. Younghee Woo, "Meaningful interaction in web-based learning: A social constructivist interpretation," Internet High. Educ., vol. 10, no. 1, pp. 15-25, 2007, doi: 10.1016/j.iheduc.2006.10.005.

[15] D. R. F. Helen L. Carlson, "Interactive Learning Models Using Videodiscs in College and Inservice Instruction," Comput. Hum. Serv., vol. 7, no. 3-4, pp. 277-293, Sep. 1990, doi: 10.1300/J407v07n03 08 .

[16] J. Saldana and J. Saldaña, The Coding Manual for Qualitative Researchers. 2009.

[17] D. Cutchins, K. Krebs, and E. Voigts, "Qualitative Data Analysis," Routledge Companion to Adapt., pp. 1-406, 2018, doi: 10.4324/9781315690254.

[18] Muslimin and Destriana, "Evaluation of curriculum implementation of 13 sports and health education teachers," Univers. J. Educ. Res., vol. 8, no. 1, pp. 27-35, 2020, doi: 10.13189/ujer.2020.080104. 